\title{
TOWARDS BREEDING LESS ALLERGENIC SPELT-WHEAT WITH LOW FODMAP CONTENT - A REVIEW
}

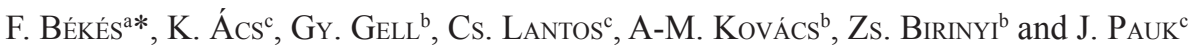 \\ ${ }^{a}$ FBFD PTY LTD, Sydney, 3/96-100 Gladstone str., North Parramatta. NSW Australia \\ ${ }^{\mathrm{b}}$ Agricultural Institute, MTA Centre for Agricultural Research, H-2462 Martonvásár, Brunszvik u. 2. Hungary \\ ${ }^{\mathrm{c}}$ Department of Biotechnology/Cereal Research Non-profit Ltd., H-6726 Szeged, Alsókikötősor 9. Hungary
}

\begin{abstract}
Consumption of "gluten-containing" diet causes disease for a significant minority of people who consume foods derived from wheat, rye, barley, and possibly oat. The fact is, however, that in several types of diseases related to the consumption of "gluten-containing" cereals, the trigger compounds are not components of gluten. The current view of medical experts is that, excluding people suffering from celiac disease, the majority of individuals who are feeling better on the "wheat-free" or "gluten-free" diet could select a food containing much healthier, low level of fermentable oligosaccharides (often called as FODMAP). To satisfy the specific health related demands of certain consumer groups, the challenge is in front of cereal breeding to develop new, "healthier" germplasms, suitable to produce such products by the food industry. This report aims to give an overview of some aspects of recent developments in this booming area, (i) summarizing the up-to-date knowledge on cereals-related health disorders; (ii) reporting on the status of developing celiac-safe cereals, and finally (iii) highlighting the potential of developing "healthier" spelt-based cereal products through the progress in an ongoing spelt breeding program.
\end{abstract}

Keywords: celiac disease, IBS, non-celiac gluten sensitivity, spelt, wheat allergy

Based on the definition of IsLAm and co-workers (2011), wheat gluten is a protein-lipidcarbohydrate complex formed as a result of specific covalent and non-covalent interactions among flour components during dough making as the components are hydrated and energy from mechanical input from the mixing process is provided. However, nowadays the terms 'gluten' and 'gluten-free' are used more widely (and wrongly) in everyday practice, the latter loosely referring to food products not containing cereal prolamin proteins, i.e. wheat gliadin and glutenin analogues.

Consumption of "gluten-containing" food causes disease for a significant minority of people who consume foods derived from wheat, rye, barley, and possibly oats. The consideration of oat as a "harmless cereal" is one of the oldest and open problems among experts. While several publications explain its potential danger as a result of contamination by other cereal, others claim that a certain proportion of celiac patients are sensitive to epitopes found in avenins, the storage proteins of oat (Pulido et al., 2009; Comino et al., 2016).

The fact is that in several types of diseases related to the consumption of "glutencontaining" cereals, the trigger compounds are not components of gluten. There is a lack of detailed knowledge about the causes of different symptoms or diseases and the terms "gluten",

* To whom correspondence should be addressed.
Phone: +61 407727 729; fax: +61 29875 4029; e-mail: firinc47@gmail.com

This is an open-access article distributed under the terms of the Creative Commons Attribution 4.0 License, which permits unrestricted use, distribution, and reproduction in any medium for non-commercial purposes, provided the original author and source are credited. 
"prolamins", "gliadin", "glutenin" not only in the minds of the consumer but also in medical practice (BRANCHI et al., 2015).

The general public in most Western countries is now aware of the potential adverse effects of cereals containing gluten with reports appearing in the lay press (BRALY \& HoGGAN, 2002; FORD, 2008; WANGEN, 2009) promoting gluten-free diets. Many of these reports fail to draw attention to the importance of appropriate diagnosis or defining the nature of the gluten "intolerance" an individual may have, hence posing a significant public relations threat to the grain industry.

Gluten-free business has been booming in the last five years in western countries. In the USA retails sales reached $\$ 10.5$ billion in 2013, and more than $\$ 15$ billion is predicted for 2016. In Australia, where more than $23 \%$ of new bakery products were marketed as glutenfree in 2014, it is expected that the gluten-free retail sales exceed $\$ 100$ million in the next five years (JARGON, 2014).

As the knowledge about the mechanisms of certain disorders is improving, we learn that the causing components of cereal products are not always gluten proteins but often soluble proteins (albumins and globulins), even soluble oligosaccharides. This fact underlines the need to understand better what type of diet is required for different sensitive individuals instead of only recommending "gluten-free" diet for them.

Commercial activity related to "gluten toxicity" and "wheat allergy" is mostly focused on "gluten-free" food. However, as more and more information is collected in the medical research, for medium or long term, the solution to solve this problem and satisfy what the different consumer groups need does not simply have traditional and "gluten-free" products on the shelf of the supermarkets. A gluten-free diet is not healthier but incomparably more expensive than the consumption of gluten-containing products (MissBACH et al., 2015). Beyond those individuals who suffer from celiac disease ( $\sim 1 \%$ of the Caucasian population), consumers with different cereal-related health disorders can tolerate products containing reduced and/or altered gluten content and reduced amounts of certain soluble carbohydrates (FODMAPs) (HALMOS et al., 2015).

To satisfy the specific health related demands of particular consumer groups, the challenge is in front of cereal breeding to develop new, "healthier" germplasms, suitable to produce such products by the food industry.

To define approachable goals, a better understanding of the different health related disorders, their prevalence and causing compounds is required not only in the relevant basic research but also in commercial cereal breeding. This report aims to give an overview of some aspects of recent developments in this booming area, summarizing the up-to-date knowledge on cereals-related health disorders, providing some information on the status of developing celiac-safe cereals, finally - by offering an example of the progress in an ongoing spelt breeding program - highlighting the potential of developing "healthier" spelt-based cereal products.

\section{Cereal-related health disorders}

The spectrum of "gluten"-related disorders can be divided into three main groups: autoimmune, allergic, and not autoimmune - not allergic disorders (SAPONE et al., 2012). Two of these disease types, the autoimmune and the allergic diseases are relatively well documented; however, further studies are needed to reveal mechanisms related to the various symptoms of allergic reactions. The autoimmune disorders include celiac disease (CD) 
(ANDERSON \& Wieser, 2006), gluten ataxia, and dermatitis herpetiformis (LAURière et al., 2006). The allergic reactions involve respiratory allergy (AmANo et al., 1998), food allergy (MilLs et al., 2004), wheat-dependent exercise-induced anaphylaxis (ARMENTIA et al., 1990), and contact urticaria (LAHTI, 1986). The adaptive and innate pathways leading to CD-specific symptoms have been described and reviewed extensively (Plugis \& KHosla, 2015).

\subsection{Celiac disease}

Symptoms of celiac disease are triggered by an abnormal response of auto-antibodies, such as antibodies to tissue-transglutaminase, or antibodies against proline- and glutamine-rich wheat gluten proteins or their barley and rye homologs (Green \& Cellier, 2007). Celiac disease shows strong association with HLA-DQ alleles, one of the most important genetic factors in developing detrimental symptoms (SoLLID et al., 2012). HLA-DQ heterodimers function as surface-type receptor proteins bound to the surface of antigen-presenting cells. The presence of HLA-DQ molecules, such as DQ2.5, DQ8, DQ2.2, is a clear marker for developing autoimmune symptoms, with modifying effects coming from genetic and environmental factors (ANDERSON et al., 2000). The different serotypes recognise different peptides.

A set of criteria can be defined for the structure of an active $\mathrm{CD}$ epitope in a cereal protein: a) a size of nine amino acids fitting into the groove of the HLA-DQ heterodimers, b) the presence of a tissue transglutaminase 2 (tTG) enzyme-binding site, c) surrounded by amino acids with defined charge and hydrophobicity (SoluID et al., 2012). Patients suffering from celiac disease produce a range of autoimmune responses to gliadins and LMW glutenins and several HMW glutenin subunits as well as their analogous polypeptides in the consumed cereal products (JuHÁsZ et al., 2012).

\subsection{Wheat allergies}

The development of wheat allergies is mediated more directly by the recognition of allergens by specific IgE epitopes bound to mast cells (CATASSI \& FASANO, 2008). Depending on the route of wheat allergen exposure, symptoms can be divided into symptoms of classic food allergy; Wheat-dependent exercise-induced anaphylaxis (WDEIA); occupational asthma (bakers' asthma), and urticaria (SAPONE et al., 2012). Typical food allergy symptoms may affect the skin, gastrointestinal or respiratory tract. Bakers' asthma, one of the most common respiratory allergies, is a significant symptom among adults working with wheat flour.

In wheat allergy, allergen-presenting B-cells and T-cells have the same level of impact and, similar to other food allergies allergic reactions, are the result of cross-links between specific immunoglobulin $\mathrm{E}$ and short peptides rich in glutamine and proline that arise from the breakdown of wheat seed proteins by endogenous proteases (SAPONE et al., 2012). This interaction stimulates basophils and mast cells to release chemical mediators, such as histamines resulting in different categories of inflammatory reactions. The allergenic regions of proteins recognised by the binding sites of IgE molecules are called IgE-binding epitopes. These epitopes can be classified into two categories, conformational and linear epitopes and both types are involved in the development of allergic reactions (AkAgawa et al., 2007). Allergenic proteins of wheat are not only prolamins $(\alpha, \beta, \gamma$, and $\omega$ gliadins, HMW, and LMW glutenin subunits) but also proteins that are not components of the gluten complex (amylases, the lipid transfer proteins (LTP), peroxidase, thioredoxin, and serine proteinase inhibitors) (TATHAM \& SHEWry, 2008). 


\subsection{Non-celiac gluten sensitivity}

Non-celiac gluten sensitivity (NCGS) was described 40 years ago, being defined as mainly abdominal symptoms related to ingestion of gluten-containing cereals (ScHuPpAN et al., 2015). There is substantial evidence that NCGS is caused by an innate immune response to wheat proteins (different from the adaptive, $\mathrm{T}$ cell-mediated response to gluten in celiac disease, or to gluten and non-gluten proteins in wheat allergy) (SAPONE et al., 2012; CATASSI et al., 2013). The study carried out by JUNKER and co-workers (2012) led to the identification of the family of amylase-trypsin inhibitors (ATIs) as triggers of innate immunity in wheat. NCGS has become a topic of increasing interest for the scientific community. The results of the survey of BRANCHI and co-workers (2015) demonstrate a certain degree of awareness of the clinical relevance of gluten-related disorders among gastroenterology specialists.

\subsection{Irritable Bowel Syndrome}

Irritable Bowel Syndrome (IBS) is a common gastrointestinal condition contributing to considerable financial burden and impact on quality of life. Till recently, therapeutic strategies, however, had disappointing efficiency but it is improved significantly by the findings of the research group led by Peter Gibson, Melbourne, Australia (GiBson et al., 2007, 2015). Because many abdominal symptoms might originate from bowel digestion altering factors that contribute to luminal digestion, particularly the osmotic load within the lumen, and the fermentative gas content might offer symptomatic benefit. Candidate substrates that are highly fermentable exerting an osmotic effect are dietary, poorly absorbed, short-chain carbohydrates collectively termed FODMAPs (Fermentable Oligosaccharides, Disaccharides, Monosaccharides, and Polyols) (SHEPHERD \& GIBSON, 2006). FODMAPs can include fructose and lactose in patients in whom these are malabsorbed polyols such as sorbitol because they are poorly absorbed by humans, as well as fructo-oligosaccharides (fructans) and galactooligosaccharides (such as raffinose) for which humans do not express suitable hydrolases and are always poorly absorbed (SHEPHERD et al., 2008). Major dietary FODMAPs include fructose and fructans. Common dietary sources of fructose are fruit and honey; sources of fructans are cereals and onion (MUIR et al., 2009; BIESIEKIERSKI et al., 2011).

The evidence base for the efficacy of the low FODMAP diet is building (SHEPHERD \& GIBSON, 2006; SHEPHERD et al., 2008) with a recent blinded placebo-controlled crossover study confirming previous studies that about $75 \%$ of patients gain clinically significant benefit (HALMOS et al., 2014). The low-FODMAP diet is increasingly being applied by health professionals in patients with IBS as first-line therapy (HALmos et al., 2014, 2015). Given the high prevalence and chronic nature of IBS, it is possible that many people will restrict intake of FODMAPs over months to years (SHEPHERD \& GiBSON, 2006).

\subsection{Prevalence of different disorders}

Overall, celiac disease affects $1 \%$ of Western communities in which the predisposing genes, HLA DQ2 and HLA DQ8, are found in approximately $30 \%$ of the population (ANDERSON \& WIESER, 2006).

Recently a large set of blood samples from randomly selected individuals $(\mathrm{n}=1145)$ (PASCO et al., 2012) was analysed by the IgE RAST method against wheat and milk antigens, and food allergy questionnaires were used with statistical analyses to establish relationships between individuals with clinical symptoms and immune responses (Vu et al., 2014). Results indicated that the prevalence of wheat allergy was $2.5 \%$ where both a positive IgE immune 
response and symptoms against wheat were observed. These results are in full agreement with similar investigations on wheat where the prevalence of wheat IgE sensitization in European countries is $2.9 \%$ (ZuidmeER et al., 2008; SiLES \& HSIEH, 2013). It was postulated that the remaining $12.8 \%(\mathrm{n}=125)$ of individuals who showed raised $\operatorname{IgE}$ antibody levels without symptoms might have a latent wheat sensitivity with the potential of developing symptoms sooner or later. The large proportion (12.9\%) of the investigated population who have symptoms associated with consumption of wheat products but did not demonstrate raised IgE may suffer from other wheat-related disorders (i.e. not IgE mediated) such as celiac disease, non-celiac gluten sensitivity (NCGS), or reaction to fructans (FODMAPs) for those with IBS.

\section{Developing celiac-safe wheat}

The amino acid sequences of gluten proteins that are responsible for triggering responses in sensitive individuals have been identified showing that they vary in distribution among and between different groups of gluten proteins (SHEWRY \& TATHAM, 2016). The detection and in particular the quantification of gluten proteins are critical not only due to their direct effect on end-use quality but also for food safety reasons. Grain composition varies between cereal genotypes and therefore leads to methodological problems in food allergen research and genotype selection in breeding for quality. The high sequence similarity and multi-species origin of prolamins coupled with limitations in the available methodologies, reviewed by HARASZI and co-workers (2011) make the accurate identification of proteins that trigger health problems and their genotypic frequency, variability and stability difficult to determine. Highresolution methods such as mass spectrometry (MS) require accurate quantitative relationships between prolamin peptide biomarkers and the final gluten/prolamin content to relate the detection of peptide mass to their protein sources. These quantitative relationships, however, are difficult to establish due to genotypic and environmental variability.

To assist peptide biomarker searches, epitope mapping, protein selection and medical studies, a database (ProPepper, https://propepper.net) was developed to contain members of the prolamin superfamily proteins identified from Poaceae species, peptides obtained with single and multi-enzyme in silico digestion as well as linear epitopes responsible for wheatrelated food disorders (JuHÁsz et al., 2015).

Knowledge of the composition and amounts of toxic and allergen epitopes present in a single wheat sample represents a significant gap and the very soon complete grain proteome datasets now available can provide the necessary information to carry out an estimation of toxicity/allergen prediction for a single cultivar. The combined use of genome sequence and toxic/allergen databases, prediction methodology, and cereal chemistry results in a better understanding of the level of toxicity present in the end-products from wheat flour. The workflow presented in the review of JuHÁsz and co-workers (2012) provides information about the number and distribution of epitopes for a single protein or a protein fraction. Also, epitopes present in the highest frequency and for the most harmful proteins can be identified. The "epitope toxicity" value obtained in this way is a significant research output from the analysis of large datasets that can be applied to the food industry.

Recently two valuable reviews summarized current research activities focusing on the status of alternative cereals and pseudocereals and their derivatives obtained by natural selection, breeding programs, and transgenic or enzymatic technology, with the potential to develop products tolerated by celiac people (Comino et al., 2013; SHEWRY \& TATHAM, 2016). 
Conventional breeding may, therefore, be used to select for gluten protein fractions with lower contents of celiac epitopes. Molecular breeding approaches can also be used to specifically down-regulate celiac-toxic proteins or mutate celiac epitopes within individual proteins. One of the known examples of this approach is the work of GIL-HuMANES and coworkers $(2008,2010)$, where RNA interference mediated gene silencing was used to downregulate the gamma and the alpha gliadins in bread wheat. Similar approach was used by Altenbach and co-workers $(2014 \mathrm{a}, \mathrm{b})$ to eliminate the most allergenic gluten proteins, the omega-5 gliadins.

The combination of the above approaches may, therefore, be used to develop "celiacsafe" wheat. However, this remains a formidable challenge due to the complex multigenic control of gluten protein composition. Furthermore, any modified kinds of wheat must retain acceptable properties for making bread and other processed foods. Not surprisingly, such celiac-safe wheat has not yet been developed despite over a decade of research.

\section{Gluten-free versus low FODMAP diet}

In a recent survey (Gluten-Free Foods IN THE U.S., 5th Edition, 2012) of those who eat gluten-free foods, $36 \%$ do so for reasons other than sensitivity, $65 \%$ because they think it is healthier, $27 \%$ because they believe that it aids weight loss, $7 \%$ do so to help reduce inflammation, and $4 \%$ do so to combat depression, only $5.7 \%$ claimed a formal medical diagnosis.

Gluten-free diet (GFD) generates many social and economic repercussions due to the ubiquity of gluten in foods (Comino et al., 2013). Meanwhile, it cannot be regarded as a healthy diet (BALAKIREVA \& ZAMYATNin, 2016). Gluten-free products are usually made with starches or refined flours characterised by low fibre content. It is known that the consumption of adequate amounts of dietary fibre is related to significant health benefits such as prevention of colon cancer, diabetes, and cardiovascular disease. Thus, GFD may lead to possible nutrient deficiencies in fibre resulting in consequent diseases. Several studies suggest pseudocereal sources of fibre instead of gluten-free products to maintain the necessary fibre content level (SATURNi et al., 2010). GFD also leads to a deficiency in vitamins C, B ${ }_{12}$, D, and folic acid (HALLERT et al., 2002), as well as microelements, most importantly calcium, magnesium, and zinc (CARUSO et al., 2013). At the same time, GFD contains high amounts of sugar and hydrogenated fats, which could result in the occurrence of hyperinsulinemia and an increased obesity risk (LAmACCHIA et al., 2014). Thus, GFD appears to be an unbalanced diet inadequate regarding both macro- and micronutrients. The current view of medical experts is that, excluding people suffering from celiac disease, the majority of individuals who are feeling better on the 'wheat-free' or 'gluten-free' diet are automatically selecting a low FODMAP diet because of choosing 'gluten-free' products (HALmos et al., 2014, 2015).

Realization of the crucial importance of FODMAP components about food-related health disorders initiated active research and development in analysing FODMAP-content, as well as utilizing food materials with low FODMAP content. Compared to the 'gluten-free' phenomena, where the problematic food sources are a relatively small group of certain cereals, the establishment of a low FODMAP diet involves considering a much wider range of plant-origin foodstuffs. In the last five years, publications (MuIR et al., 2007, 2009; BIESIEKIERSKI et al., 2011) and even computer and mobile phone applications (http://www. 
med.monash.edu.au /cecs/gastro/fodmap/iphone-app.html) have been published to help to develop custom-designed low FODMAP diets.

Traditional cereals (wheat, barley, and in particular rye) are relatively rich in FODMAPs and therefore food products made from them are not recommended for low FODMAP diets.

Compared to bread wheat, spelt (Triticum aestivum subsp. spelta) contains significantly lower amounts of fructose and fructans. But even more important is that there is around a fivefold larger inter-varietal difference among spelt varieties compared to those found among bread wheat genotypes (BÉKÉs, 2015). It provides the basis for screening the spelt cultivars for low FODMAP content.

\section{Spelt, a nutritive cereal}

Molecular evidence indicates that spelt (T. aestivum ssp. spelta (L.) Thell.) $(2 \mathrm{n}=6 \mathrm{x}=42$, genome $=\mathrm{AABBDD})$ are derived from hybridization events between non-free threshing tetraploid wheat $(2 \mathrm{n}=4 \mathrm{x}=28$, genome $=\mathrm{AABB})$ and free-threshing hexaploid wheat. Most of the hulled wild wheats and hexaploid subspecies such as spelta, macha, and vavilovii have a recessive allele $(\mathrm{q})$ at the $\mathrm{Q}$ locus that conditions major domestication traits in wheat (FARIS, 2014). Extensive systematic breeding and selection led to the development of free-threshing and high-yielding varieties of spelt-wheat having the wide adaptability to different agroclimatic conditions and resulted in the replacement of most of the low-yielding traditional landraces and subspecies. Now, in most parts of the world, spelt has been superseded by common wheat (T. aestivum ssp. aestivum) and is being grown as a marginal or niche crop with low inputs. After many years of marginal cultivation, recent interest in the use of spelt for ecologically grown food has led to a resurgence in its cultivation. In fact, the food use of spelt has been a tradition in Europe, particularly in Germany where it is widely used in many grain-based foods (CUBADDA \& MARCONI, 2002). In the last 10-15 years several excellent works have been published in relation to the evolution, genetics, physiology, and the $\mathrm{G} \times \mathrm{E}$ effects on quality of spelt (BLATTER et al., 2004; FöRSTER et al., 2013, 2014).

Spelt demonstrates a higher resistance to environmental factors than common wheat and can be cultivated in harsh ecological conditions, without the use of pesticides (RAMAN et al., 2008). Moreover, spelt can grow on poorly drained and low-fertility soils and therefore is a suitable crop for organic farming (BONAFACCIA et al., 2002). In the past, spelt has not been targeted for systematic breeding; the objectives for improvement have only recently been identified (NEESON et al., 2008).

In the last decade, spelt is becoming a valuable crop due to its reputation as a healthy food not for celiacs but especially for patients with wheat allergies (GALOVA \& KNOBLOCHOVA, 2001; Elía et al., 2004) and in confectionary. Spelt flour is also reputed to possess a unique flavour and to be more nutritious than bread wheat (CAMPBELL, 1997). Generally, spelt products such as bread attract a higher price in the marketplace, especially organic products.

The chemical, nutritive, and functional properties of spelt wheats compared to $T$. aestivum wheats have been reported in numerous publications in the last decade, reviewed recently by ESCARNOT and co-workers (2012). Results showed that, on average, spelt whole meals and milling fractions were higher in lipids and unsaturated fatty acids as compared to wheat, whereas tocopherol content was lower in spelt, suggesting that the higher lipid content of spelt may not be related to a higher germ proportion. Although milling fractionation produced similar proportions of flour and bran in spelt and wheat, it was found that ash, 
copper, iron, zinc, magnesium, and phosphorus contents were higher in spelt samples, especially in aleurone-rich fine bran and in coarse bran. Even though phosphorus content was higher in spelt than in wheat brans, phytic acid content showed the opposite trend and was $40 \%$ lower in spelt versus wheat fine bran, which may suggest that spelt has either a higher endogenous phytase activity or a lower phytic acid content than wheat. The results of the study of Ruibal-MENiETA and co-workers (2005) give important indications of the real nutritional value of spelt compared to wheat. Moreover, it was shown by GOMEZ-BECERRA and co-workers (2010) that the $\mathrm{Ca} / \mathrm{Fe}$ ratio, combined with that of oleate/palmitate, provides a highly discriminating tool to authenticate spelt from wheat flours and to face the growing issue of spelt-flour adulteration. The results indicated that spelt is a highly promising source of genetic diversity for grain protein and mineral nutrients, particularly for $\mathrm{Zn}$ and Fe.

The spelt-based products are easily digestible and have a slightly higher protein content than wheat. The main difference in the nutritive value of spelt flours is the variation in the amount and type of grain proteins, especially the prolamins (GAlli et al., 2000; SHewry, 2002). There has been anecdotic clinical evidence for a long time that a large proportion of non-celiac disease patients suffering from wheat-related health disorders can tolerate products made from certain spelt varieties. Recently the first research paper with robust experimental and statistical results also demonstrated this important observation (ARMENTIA et al., 2012).

Because FODMAP components are located mostly in the endosperm of the grains, reducing the milling yield, producing less bran in the flour, does not improve the FODMAP level. The baking technology, on the other hand, has a significant effect because yeast metabolizes a certain amount of soluble carbohydrates during fermentation. So, FODMAP content in the final product can be altered both by the amount of yeast applied in the bread formulation, and/or the length of fermentation. Compared to yeasted dough products, sourdough technology has an even more significant effect in reducing the FODMAP level.

\section{Breeding less allergenic spelt-wheat with low FODMAP content}

An Australian selected and grown spelt line ("GWF spelt") was successfully selected with significantly lower FODMAP content. The FODMAP content of the baking products of this line - using an optimised formulation and technology - was considerably lower than the threshold defined for low FODMAP products (Muir et al., 2014).

Interestingly, the same line was found to have significantly less immune reactivity than any wheat and other spelt cultivars to people suffering from wheat sensitivity (Vu et al., 2014). It was also found that the albumin-globulin protein composition of GWF spelt is different from other wheat and wheat-related species (VU, 2014). One of these differences has been identified as a mutation in a CACTA retrotransposon region tightly linked to a gene coding a beta-expansin protein in many wheat and spelt germplasms (BREEN et al., 2010). The beta-expansins, a protein family of closely related non-enzymatic proteins found in plant cell walls, are known pollen allergens. This alteration in the soluble protein composition was claimed to be one of the reasons for the significantly lower immune reactivity of GWF spelt for wheat sensitive individuals (Vu et al., 2014). The mutation in the expansin gene alone does not explain the lower immune reactivity but could be utilised as a marker for the unusual soluble protein composition found in GWF spelt. This altered protein composition could be related to the lower immune reactivity, observed. 
The potential candidate source for making cereal products with dual health benefits has been recognised by several bakeries in Australia. A closed production line has been developed, including contract growing of GWF spelt with strict guidelines to avoid any contamination of the grain. A small milling capacity has been established with a particular care of cleaning the whole technology prior GWF spelt milling. A PCR-based procedure has been developed to detect the above-mentioned mutation in the expansin gene (SUTER \& BÉKÉs, 2012) to screen for any contamination in the grain or flour samples caused by any other cereals with the wild type expansin protein. This procedure is utilised for quality assurance purposes. FODMAP content of flour and their products (sourdough bread with unique formulation) is monitored by an expert laboratory. Flour from this unique spelt source, characterised by low FODMAP and lower immune reactivity, is currently being supplied to Australian artisan bakeries under the name of Hildegard spelt flour, after St Hildegard von Bingen, nun, writer, composer, philosopher, Christian mystic, visionary, and polymath from the $11^{\text {th }}$ century who first realised the health related advantages of spelt.

Preliminary experiences provide some evidence to support the dual health benefits of this spelt line. The question remains as to whether this finding is associated with the apparent lower allergenicity of spelt for those with wheat allergy. An answer requires a double-blind, randomized placebo-controlled clinical trial, comparing the allergic symptoms and IgE levels caused by the consumption of wheat and GWF spelt products, involving both, those that eat predominantly wheat and those who have replaced spelt for wheat in their diet.

Based on the positive experiences on evaluating GWF spelt, a pre-breeding activity has been initiated in Hungary to screen large spelt populations, selecting lines with low FODMAP content and suitable processing quality. The chosen lines are further investigated by looking for genotypes containing the expansin-mutation applying the PCR-based test of SUTER and BÉKÉs (2012) and ELISA based techniques (BoDINIER et al., 2008), respectively. As it is demonstrated in a preliminary survey carried out on 105 spelt lines (PAUK et al., unpublished results), FODMAP content of spelt lines available in the Carpathian basin show large variation $(0.7-1.8 \mathrm{~g}$ fructan in $100 \mathrm{~g}$ grain). More than $10 \%$ of the lines contain equal or lower level of fructan than the Australian control, found to be beneficial in low FODMAP diet.

To increase the speed of generation changing in breeding and to improve the homogeneity of newly selected spelt-lines an effective in vitro androgenesis method was developed in spelt wheat (LANTOS et al., 2016). The anther culture method was carried out with a new Hungarian genotype (GK Fehér), but the protocol was tested by other three spelt registered varieties, too. The production of embryo-like structures (ELS) was $62 \mathrm{ELS} / 100$ anthers, from which we were able to regenerate green plantlets. The percentage of green plantlets production was $89.0 \%$ among the regenerated plantlets while the number of albinos was limited (3.8/100 anthers). Altogether, over one-thousand in vitro green plantlets were produced from anther culture of different spelt genotypes. Based on ploidy-level analyses from the haploid plantlets the doubled haploid plantlets were produced via colchicine treatment (PAUK et al., 2003) and getting seed after spontaneous diploidization. The colchicine treated and spontaneous DH plants were grown up in the greenhouse. The in vitro haploid induction system was integrated into the breeding programme of spelt-wheat in the same way as we did in common wheat (PAuk et al., 2004). 


\section{Conclusions}

The above procedure of producing a cereal line with health benefits can be used as an example, indicating how to manage (protect, monitor, and check) the quality of the final product from contamination by any other cereal material from the field to the bakery. This type of issues will hopefully appear shortly when germplasm with altered gluten and/or nongluten protein composition and proven reduced allergenicity will be selected or produced.

Compared to the ultimate task - developing celiac-safe cereals - it is a much more realistic approach to developing cereals with largely reduced allergenicity and with low FODMAP content. Such products can be consumable for most of the wheat sensitive customers but not for the celiac patients.

The development, manufacturing and commercial availability of such products require further detailed basic and applied research in relation to developing reliable, cost-effective, and high-throughput analytical tools to monitor the presence/absence and quantity of certain key components of the source material, the intermediates, and the final product through the whole production chain from the farm to the supermarket. However, the development of the infrastructure for the production and commercialization of a more versatile, healthier cereal product basis is one of the several requirements needed to deal with the complex issue of providing suitable food for people suffering from cereal-based health disorders. The legislative environment must be altered to allow the production/commercialization of products with low/altered gluten content, defining thresholds of certain key components, giving instructions of analytical procedures, labelling, regulating, and policing the very often misleading media-based marketing, etc. But ultimate need is the better communication, collaboration among plant science, medical research and practice, as well as grain industry and the permanent, honest, and up-to-date information of the customer.

This study was supported within project OTKA-K 16-119835, funded by the National Research, Development and Innovation Office.

\section{References}

Akagawa, M., Handoyo, T., Ishit, T., Kumazawa, S., Morita, N. \& Suyamam, K. (2007): Proteomic analysis of wheat flour allergens. J. Agr. Food Chem., 55, 6863-6870.

Altenbach, S.B., Tanaka, C.T. \& Allen., P.V. (2014a): Quantitative proteomic analysis of wheat grain proteins reveals differential effects of silencing of omega-5 gliadin genes in transgenic lines. J. Cereal Sci., 59, 118125.

Altenbach, S.B., Tanaka, C.T. \& Seabourn, B.W. (2014b): Silencing of omega-5 gliadins in transgenic wheat eliminates a major source of environmental variability and improves dough mixing properties of flour. BMC Plant Biol., 14(1), 1-13.

Amano, M.H., Ogawa, K., Kojima, T., Kamidaira, S., Suetsugu, M., Yoshihama, T., Satoh, T., Samejima, I. \& Matsumoto, M. (1998): Identification of the major allergens in wheat flour, responsible for baker's asthma. Biochem. J., 330, 1229-1234.

Anderson, R.P., Degano, P., Godkin, A.J., Jewell, D.P. \& Hill, A.V.S. (2000): In vivo antigen challenge in celiac disease identifies a single transglutaminase-modified peptide as the dominant A gliadin T-cell epitope. Nat. Med., 6, 337-342.

ANDERson, R.P. \& Wieser, H. (2006): Medical applications of gluten-composition knowledge. -in: WrigLey, C.W., BéKés, F. \& Bushuk, W. (Eds) Gliadin and glutenin: The unique balance of wheat quality. AACCI Press, St Paul, pp. 387-409. 
Armentia, A., Martin-Santos, J.M. \& Blanco, M. (1990): Exercise induced anaphylaxis reaction to grain flours. Ann. Allergy, 65, 149-151.

Armentia, A., Martin, S., Diaz-Perales, A., Palacin, A. \& Martín-Armentia, M. (2012): A possible hypoallergenic cereal in wheat food allergy and baker's asthma. Am. J. Plant Sci., 3, 1779-1781.

BALAKIREVA, A. \& Zamyatnin, A.A. (2016): Properties of gluten intolerance: Gluten structure, evolution, pathogenicity and detoxification capabilities. Nutrients, 8, 644 .

BéKés, F. (2015): Health related quality attributes of wheat. -in: PAuK, J. (Ed.) Proc. $3^{\text {rd }}$ Conference of Cereal Biotechnology and Breeding / (CBB3), Akadémiai Kiadó, Budapest, pp. 1-3.

Biesiekierski, J.R., Rosella, O., Rose, R., Liels, K., Barrett, J.S., Shepherd, S.J., Gibson, P.R. \& Muir, J.G. (2011): Quantification of fructans galacto-oligosaccharides and other short-chain carbohydrates in processed grains and cereals. J. Hum. Nutr. Diet, 24, 154-176.

Blatter, R.H., Jacomet, S. \& Schlumbaum, A. (2004): About the origin of European spelt (Triticum spelta L.): Allelic differentiation of the HMW Glutenin B1-1 and A1-2 subunit genes. Theor. Appl. Genet., 108, 360-367.

Bodinier, M., Brossard, C., Triballeau, S., Morisset, M., Guerin-Marchand, C., Pineau, F., Coppet, F., MoneretVautrin, D.A., Blank, U. \& Denery-PapinI, S. (2008): Evaluation of an in vitro mast cell degranulation test in the context of food allergy to wheat. Int. Arch. Allergy Imm., 146, 307-320.

Bonafaccia, G., Galli, V., Francisci, R., Mair, V., Skrabanja, V. \& Kreft, I. (2002): Characteristics of spelt wheat products and nutritional value of spelt wheat-based bread. Food Chem., 68, 437-441.

Braly, J. \& Hoggan, R. (2002): Dangerous grains. Why gluten cereal grains may be hazardous to your health. Penguin Group, New York, 272 pages.

Branchi, F., Ferretti, F., Norsa, L., Roncoroni, L., Conte, D., Bardella, M.T. \& Elli, L. (2015): Management of nonceliac gluten sensitivity by gastroenterology specialists: Data from an Italian survey. Biomed. Res. Int., 2015, http://dxdoiorg/101155/2015/530136

Breen, M., Li, D., Dunn, D.S., Békés, F., Kong, X., Zhang, J., Jia, J., Wicker, T., Mago, R., Ma., W, Bellgard, M. \& ApPeLs, R. (2010): Wheat beta-expansin (EXPB11) genes: Identification of the expressed gene on chromosome 3BS carrying a pollen allergen domain. BMC Plant Biol., 10, 99.

CAmpBell, K.G. (1997): Spelt: Agronomy, genetics and breeding. Plant Breed Rev., 15, 187-213.

Caruso, R., Pallone, F., Stasi, E., Romeo, S. \& Monteleone, G. (2013): Appropriate nutrient supplementation in celiac disease. Ann. Med., 45, 522-531.

Catassi, C., Bai, J.C., Bonaz, B., Bouma, G., Calabro, A. \& Carroccio, A. (2013): Non-celiac gluten sensitivity: the new frontier of gluten related disorders. Nutrients, 5, 3839-3853.

Catassi, C. \& Fasano, A. (2008): Celiac disease. -in: Arendt, E.K. \& Dal Bello, F. (Eds) Gluten-free cereal products and beverages. Academic Press San Diego, pp. 1-28.

Comino, I., Bernardo, D., Bancel, E., Lourdes Moreno, M., Sanchez, B., Barro, F., Suligoj, T., Ciclitira, P.J., Cebolla, A., Knight, S.C., Branlard, G. \& Sousa, C. (2016): Identification and molecular characterization of oat peptides implicated on celiac immune response. Food Nutr. Res., 60, 30324.

Comino, I., Moreno, M., Real, A., Rodriguez-Herrera, A., Barro, F. \& Sousa, C. (2013): The gluten-free diet: Testing alternative cereals tolerated by celiac patients. Nutrients, 5, 4250-4268.

Cubadda, R. \& Marconi, E. (2002): Spelt wheat. -in: Belton, P. \& Taylor, J. (Eds) Pseudocereals and less common cereals. Grain properties and utilization potential. Springer, Berlin, Heidelberg, pp. 153-177.

Elía, M., Moralejo, M., Rodríguez-Qujuano, M. \& Molina-Cano, J.-L. (2004): Spanish spelt: a separate gene pool within the spelt germplasm. Plant Breeding, 123, 297-299.

Escarnot, E., Jacquemin, J.-M., Agneessens, R. \& Paquot, M. (2012): Comparative study of the content and profiles of macronutrients in spelt and wheat (a review). Biotechnol. Agron. Soc. (BASE), 16, 243-256.

FARIS, J.D. (2014): Wheat domestication: Key to agricultural revolutions past and future. -in: TuBerosa, R. (Ed.) Genomics of plant genetic resources. Springer, Dordrecht, pp. 439-464.

FoRD, R. (2008): The gluten syndrome is wheat causing you harm? RRS Global LT, Christchurch, 192 pages.

Förster, S., Schumann, E., Baumann, M. \& Pillen, K.P. (2013): Copy number variation of chromosome 5A and its association with $\mathrm{Q}$ gene expression, morphological aberrations, and agronomic performance of winter wheat cultivars. Theor. Appl. Genet., 126, 3049-3063.

Förster, S., Schumann, E., Pillen, K. \& Weber, W.E. (2014): Genetic and environmental effects on the occurrence of speltoids in winter wheat cultivars. Plant Breeding, 133, 442-447.

Galli, G., Francisci, V., Mair, R., Skrabanja, V. \& Kreft, I. (2000): Characteristics of spelt wheat products and nutritional value of spelt wheat-based bread. Food Chem., 68, 437-441.

Galova, Z. \& KNoblochova, H. (2001): Biochemical characteristics of five spelt wheat cultivars (Triticum spelta L). Acta Fytotechn. Zootechn., 4, 85-86. 
Gibson, P.R., Newnham, R., Barrett, J.S., Shepherd, S.J. \& Muir, J.G. (2007): Review article: Fructose malabsorption and the bigger picture. Aliment. Pharm. Ther., 25, 349-363.

Gibson, P.R., Varney, J., Malakar, S. \& Muir, J.G. (2015): Food components and irritable bowel syndrome. Gastroenterology, 148, 1158-1174.

Gil-Humanes, J., Pistón, F., Hernando, A., Álvarez, J.B., Shewry, P.R. et al. (2008): Silencing of $\gamma$-gliadins by RNA interference (RNAi) in bread wheat. J. Cereal Sci., 48, 565-568.

Gil-Humanes, J., Pistón, F., Tollefsen, S., Sollid, L.M. \& Barro, F. (2010): Effective shutdown in the expression of celiac disease-related wheat gliadin T-cell epitopes by RNA interference. P. Natl. Acad. Sci. USA, 107, 17023-17028. doi: 10.1073/pnas.1007773107

Gluten-Free Foods in the U.S., 5th Edition, 2012. https://www.packagedfacts.com/Gluten-Free-Foods-8108350/

Gomez-Becerra, H.F., Erdem, H., Yazici, A., Tutus, Y., Torun, B., Ozturk, L. \& Cakmak, I. (2010): Grain concentrations of protein and mineral nutrients in a large collection of spelt wheat grown under different environments. J. Cereal Sci., 52, 342-349.

Green, P.H.R. \& Cellier, M.D.B. (2007): Celiac disease. New Engl. J. Med., 357, 1731-1743.

Hallert, C., Grant, C., Grehn, S., Granno, C., Hulten, S., Midhagen, G., Strom, M., Svensson, H. \& Valdimarsson, T. (2002): Evidence of poor vitamin status in celiac patients on a gluten-free diet for 10 years. Aliment. Pharm. Ther., 16, 1333-1339.

Halmos, E.P., Power, V.A., Shepherd, S.J., Gibson, P.R. \& Muir, J.G. (2014): A diet low in FODMAPs reduces symptoms of irritable bowel syndrome. Gastroenterology, 146, 67-75.

Halmos, E.P., Christophersen, C.T., Bird, A.R., Shepherd, S.J., Gibson, P.R. \& Muir, J.G. (2015): Diets that differ in their FODMAP content alter the colonic luminal microenvironment. Gut, 64, 93-100.

Haraszi, R., Chassaigne, H. \& Maquet, A. (2011): Analytical methods for detection of gluten in food - method developments in support to the legislations on labelling of foodstuffs. J. AOAC Int., 94, 1006-1025.

Islam, S., Ma, W., Yan, G., BéKés, F. \& Appels, R. (2011): Modifying processing and health attributes of wheat bread through changes in composition genetics and breeding. -in: CAUvain, S.P. \& Tran, B. (Eds) Bread making, improving quality $2^{\text {nd }}$ ed. Woodhead Publishing Limited, Cambridge, pp. 259-296.

JARGON, J. (2014): The gluten-free craze: Is it healthy? The Wall Street Journal, 14 June 2014

Juhász, A., Gell, Gy., BéKés, F. \& BalÁzs, E. (2012): The epitopes in wheat proteins for defining toxic units relevant to human health. Funct. Integr. Genomics, 12, 585-598.

Juhász, A., Haraszi, R. \& Maulis, Cs. (2015): ProPepper: a curated database for identification and analysis of peptide and immune-responsive epitope composition of cereal grain protein families. Database, 2015, 1-16, doi: 101093/database/bav100

Junker, Y., Zeissig, S., Kim, S.J., Barisani, D., Wieser, H. \& Leffler, D.A. (2012): Wheat amylase trypsin inhibitors drive intestinal inflammation via activation of the toll-like receptor. J. Exp. Med., 209, 2395-2408.

LaHti, A. (1986): Contact urticaria to plants. Clin. Dermatol., 4, 127-136.

Lamacchia, C., Camarca, A., Picascia, S., Di Luccia, A. \& Gianfrani, C. (2014): Cereal-based gluten-free food: How to reconcile nutritional and technological properties of wheat proteins with safety for celiac disease patients. Nutrients, 6, 575-590.

Lantos, C., Jenes, B., Bóna, L., Cserháti, M. \& Pauk, J. (2016): High frequency of doubled haploid plant production in spelt wheat. Acta Biol. Cracov. Bot., 58(2), 107-112.

Laurière, M., Pecquet, C., Bouchez-Mahiout, I., Snegaroff, J., Bayrou, O., Raison-Peyron, N. \& Vigan, M. (2006): Hydrolyzed wheat proteins present in cosmetics can induce immediate hypersensitivities. Contact Dermatitis, 54, 283-289.

Mills, E.N.C., Jenkins, J.A., Alcocer, M.J.C. \& Shewry, P.R. (2004): Structural biological and evolutionary relationships of plant food allergens sensitizing via the gastrointestinal tract. Crit. Rev. Food. Sci. Nutr., 44, $379-407$.

Missbach, B., Schwingshackl, L., Billmann, A., Mystek, A., Hickelsberger, M., Bauer, G. \& Konig, J. (2015): Gluten-free food database: the nutritional quality and cost of packaged gluten-free foods. PeerJ, 3, e1337 DOI107717/peerj1337

Muir, J.G., Mills, J., Suter, D., BéKés, F., Liels, K., Yao, L.K. \& Gibson, P.R. (2014): FODMAPS in gluten-free grains may explain improved gastrointestinal symptoms in IBS on a gluten-free diet. Proc. Ann. Sci. Meeting Nutr. Soc. Australia,"Nutrition: Challenges and Opportunities", J. Nutr. Intermed. Metab.. 1, 14-15.

Muir, J.G., Rose, R., Rosella, O., Liels, K., Barrett, J.S., Shepherd, S.J. \& Gibson, P.R. (2009): Measurement of short-chain carbohydrates in common Australian vegetables and fruits by high-performance liquid chromatography. J. Agr. Food Chem., 57, 554-565.

Muir, J.G., Shepherd, S.J., Rosella, O., Rose, R. \& Gibson, P.R. (2007): Fructan and free fructose content of common Australian vegetables and fruit. J. Agr. Food Chem., 55, 6619-6627. 
Neeson, R., Evans, J., Burnett, V., Luckett, D., Wellings, C., Taylor, H., Raman, H., Van Meeuwen, E. \& Bowden, P. (2008): Optimising the quality and yield of spelt under organic production in SE Australia. Proc $14^{\text {th }}$ Australian Society of Agronomy Conference’ ASAC, Adelaide, pp. 24-31.

Pasco, J.A., Nicholson, G.C. \& Kotowicz, M.A. (2012): Cohort profile: Geelong osteoporosis study. Int. J. Epidemiol., 41, 1565-1575.

Pauk, J., Hassan, M.S., Puolimatka, M., Lantos, C., Mihály, R., Mesterházy, Á., Kertész, Z. \& Matuz, J. (2004): Microspore- and anther culture improvements for wheat breeding. -in: MujiB, A., Cho, M.J., Predieri, S. \& BANERJEe, S. (Eds) In vitro application in crop improvement: Recent progress. Science Publishers Inc., USA, Enfield, New Hampshire, pp. 131-151.

Pauk, J., Minály, R. \& Puolimatka, M. (2003): Protocol for wheat (Triticum aestivum L.) anther culture. -in: Kasha, K. \& Maluszynski, M. (Eds) Doubled haploid production in crop plants. Kluwer Academic Publisher, Dordrecht/Boston/London, pp. 59-64.

Plugis, M.P. \& Khosla, C. (2015): Therapeutic approaches for celiac disease. Best Pract. Res. Cl. Ga., 29, 503-521.

Pulido, O.M., Gillespie, Z., Zarkadas, M., Dubois, S., Vavasour, E., Rashid, M., Switzer, C. \& Godefroy, S.B. (2009): Introduction of oats in the diet of individuals with celiac disease: a systematic review. Adv. Food Nutr. Res., 57, 235-285.

Raman, H., Rahman, R., Luckett, D., RAman, R., BéKés, F., LÁng, L. \& Bedö, Z. (2008): Characterisation of genetic variation for aluminium resistance and polyphenol oxidase activity in genebank accessions of spelt wheat. Breeding Sci., 59, 373-381.

Ruibal-Menieta, N.L., Delacroix, D.L., Mignelot, E., Picke, J.M., Marques, C., Meurens, M., Delzenne, N.M. \& LARondelle, Y. (2005): Spelt (Triticum aestivum ssp. spelta) as a source of breadmaking flours and bran naturally enriched in oleic acid and minerals but not phytic acid. J. Agr. Food Chem., 53, 2751-2759.

Sapone, A., Bai, J.C., Ciacci, C., Dolinsek, J., Green, P.H.R., Hadjivassiliou, M., Kaukinen, K., Rostami, K., Sanders, D.S., Schumann, M., Ullrich, R., Villaltam, D., Voltam, U., Catassi, C. \& Fasano, A. (2012): Spectrum of gluten-related disorders: Consensus on new nomenclature and classification. BMC Med., 10, 13 doi:101186/1741-7015-10-13

Saturni, L., Ferretti, G. \& Bacchetti, T. (2010): The gluten-free diet: Safety and nutritional quality. Nutrients, 2, 16-34.

Schuppan, D., Pickert, G., Ashfaq-Khan, M. \& Zevallos, V. (2015): Non-celiac wheat sensitivity: Differential diagnosis triggers and implications. Best Pract. Res. Cl. Ga., 29, 469-476.

SHEPHERD, S.J. \& GiBSON, P.R. (2006): Fructose malabsorption and symptoms of IBS: Guidelines for effective dietary management. J. Am. Diet. Assoc., 106, 1631-1639.

Shepherd, S.J., Parker, F.C., Muir, J.G. \& Gibson, P.R. (2008): Dietary triggers of abdominal symptoms in patients with IBS: Randomized placebo-controlled evidence. Clin. Gastroenterol. H., 6, 765-771.

SHEwry, P.R. (2002): The major seed storage proteins of spelt wheat, sorgum millets and pseudocereals. -in: BELTON, P. \& TAYlor, J. (Eds) Pseudocereals and less common cereals: Grain properties and utilization potential. Springer, Berlin, Heidelberg, pp. 1-24.

Shewry, P.R. \& TAтHAM, A.S. (2016): Improving wheat to remove celiac epitopes but retain functionality. J. Cereal Sci., 67, 12-21.

SiLES, R.I. \& Hsien, F.H. (2013): Allergy blood testing: A practical guide for clinicians. Clev. Clin. J. Med., 78, 585-592.

Sollid, L.M., Qiao, S.W., Anderson, R.P., Gianfrani, C. \& Koning, F. (2012): Nomenclature and listing of celiac disease relevant gluten T-cell epitopes restricted by HLA-DQ molecules. Immunogenetics, 64, 455-460.

Suter, D.A.I. \& BÉKÉs, F. (2012): Wheat immunoreactivity. Australian Patent http://v3 espacenetcom/ publicationDetails/ biblio?CC $=\mathrm{HU} \& \mathrm{NR}=\mathrm{AU} 2011000468$

TAtham, A.S. \& Shewry, P.R. (2008): Allergy to wheat and related cereals. Clin. Exp. Allergy, 38, 1712-1726.

Vu, N.T. (2014): Comparative analysis of the soluble wheat proteins and human health. PhD Thesis. Sydney University. Sydney, Australia, 421 pages.

Vu, N.T., Chin, J., Pasco, J.A., Kovács, A., Wing, L.W., Békés, F. \& Suter, D.A.I. (2014): The prevalence of wheat and spelt sensitivity in a randomly selected Australian population. Cereal Res. Comm., 43, 97-107.

WANGEn, S. (2009): Healthier without wheat. A new understanding of wheat allergies, Celiac disease and non-celiac gluten intolerance. Innate Health Publishing, Seattle, 285 pages.

Zuidmeer, L., Goldhahn, K., Rona, R.J., Gislason, D., Madsen, C., Summers, C., Sodergren, E., Dahlstrom, J., Lindner, T., Sigurdardottir, S.T., McBride, D. \& Keil, T. (2008): The prevalence of plant food allergies: A systematic review. J. Allergy Clin. Immun., 121, 1210-1218. 